\title{
Erratum to: A Two-Way Steady-State Pharmacokinetic Interaction Study of Doravirine (MK-1439) and Dolutegravir
}

Matt S. Anderson ${ }^{1}$ Sauzanne Khalilieh ${ }^{1} \cdot$ Ka Lai Yee ${ }^{1} \cdot$ Rachael Liu $^{1}$.

Li Fan ${ }^{1}$ - Matthew L. Rizk ${ }^{1}$ - Vedangi Shah ${ }^{1}$ - Azra Hussaini ${ }^{2}$ Ivy Song ${ }^{3}$.

Lisa L. Ross ${ }^{4} \cdot$ Joan R. Butterton ${ }^{1}$

Published online: 10 February 2017

(c) Springer International Publishing Switzerland 2017

\section{Erratum to: Clin Pharmacokinet}

DOI 10.1007/s40262-016-0458-4

Figures 2 and 3, and their corresponding legends were incorrect and were corrected in this erratum.

Figures 2 and 3 should appear as follows:

The online version of the original article can be found under doi:10.1007/s40262-016-0458-4.

Matt S. Anderson

matt_anderson@merck.com

1 Merck \& Co., Inc., 2000 Galloping Hill Rd, Kenilworth, NJ 07033, USA

2 PAREXEL, Baltimore, MD, USA

3 GlaxoSmithKline, Research Triangle Park, NC, USA

4 ViiV Healthcare, Research Triangle Park, NC, USA 
Fig. 2 Individual analyte parameter ratios for dolutegravir (a) and doravirine (b) with geometric mean ratios and $90 \%$ confidence intervals following multiple-dose administration with and without the additional treatment [doravirine and dolutegravir, respectively (perprotocol population)]. $A U C_{0-24}$ area under the plasma

concentration-time curve from dosing to $24 \mathrm{~h}$ post-dose, $C_{24}$ concentration $24 \mathrm{~h}$ post-dose, $C_{\max }$ maximum concentration a

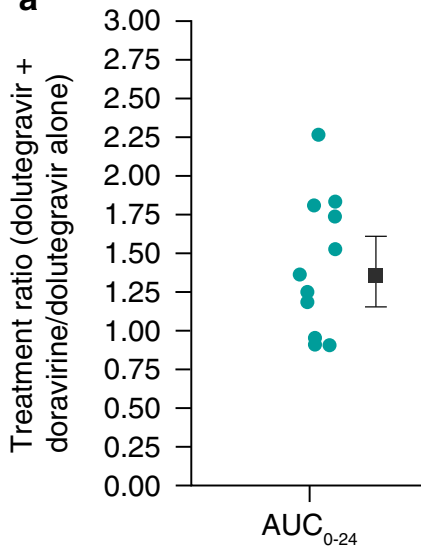

Subject ratio

- Geometric mean ratios

-

○.

은

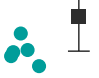

- b

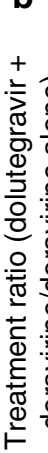

2.25

200

1.75

1.50

1.25
1.00

0.75

0.50

0.25

0.00
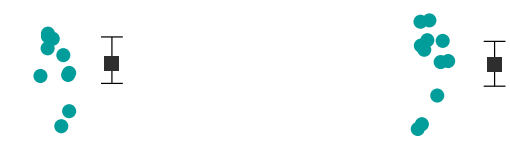

Subject ratio

- Geometric mean ratios

$\bullet$

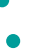

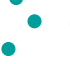

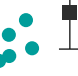

$C_{\text {max }}$

Parameter 
Fig. 3 Arithmetic mean steadystate doravirine plasma concentration profile with and without co-administration with dolutegravir: a linear scale $( \pm \mathrm{SD})$ and $\mathbf{b}$ semi-log scale, $S D$ standard deviation
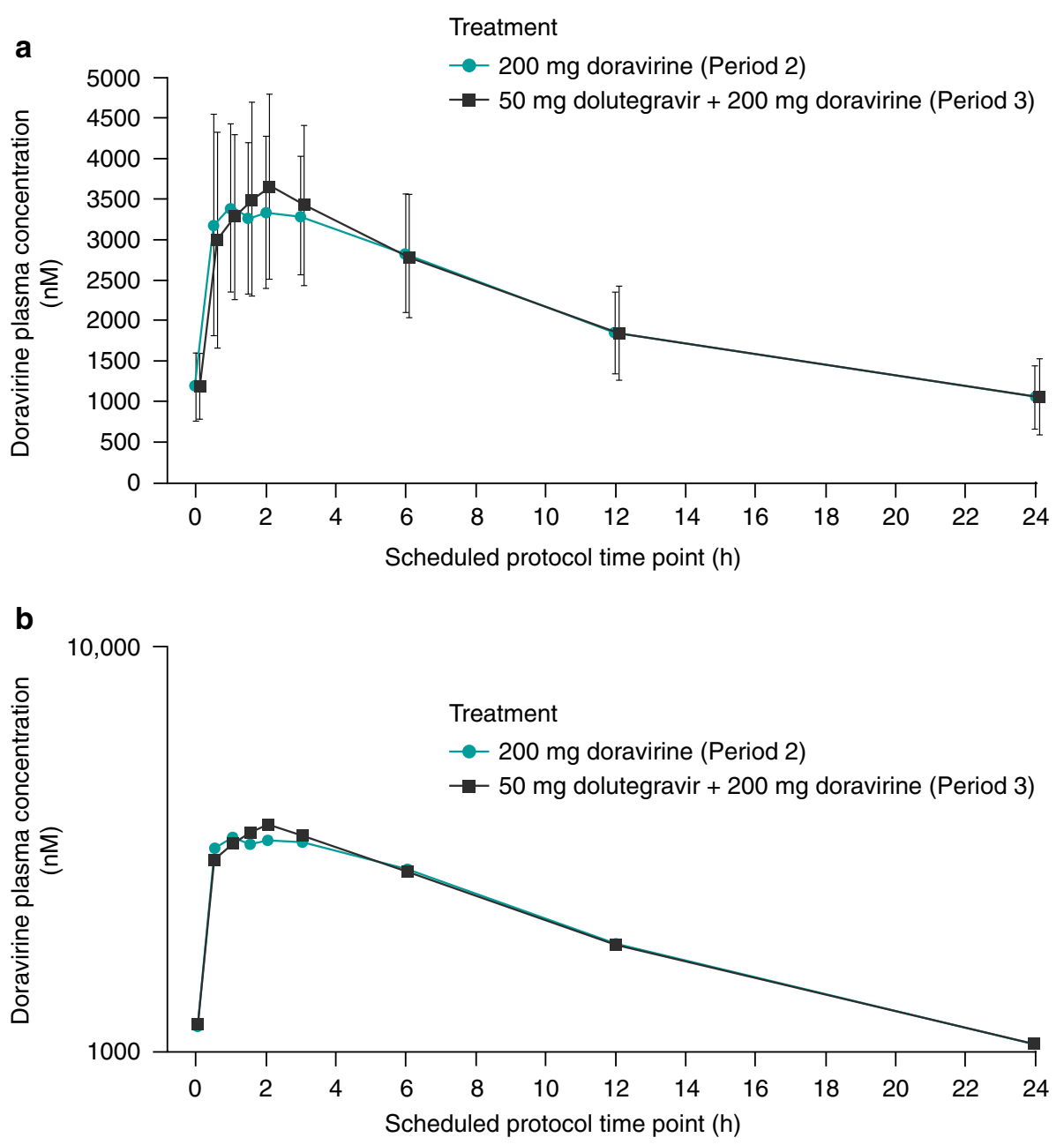